\title{
Mandatory reporting of gunshot wounds: rebuttal
}

\author{
Merril A. Pauls, Jocelyn Downie
}

ß See related articles pages 1255 and 1256

$W$ e applaud the Executive of the Section on Emergency Medicine of the Ontario Medical Association for their call to action. We support many of the points made in their position statement but ultimately believe that a law for the mandatory reporting of gunshot wounds will do more harm than good. Ovens describes the support the position statement has garnered, but he fails to mention that neither the Canadian Association of Emergency Physicians nor the Canadian Medical Association support such mandatory reporting. ${ }^{1,2}$

We recognize that some suicidal patients will pose an ongoing risk to themselves or others and that their access to guns must be addressed. However, a psychiatrist, not the police, should evaluate this risk. Ovens cites concerns that one-third of firearm-related accidents involve children. However, current laws regarding child protection allow physicians to report these cases - to child and family services workers, not to the police.

We encourage physicians to support police investigations within the context of current Canadian laws and professional regulations. Although Ovens claims that he is not advocating for physicians to become crime fighters, that is exactly what we believe a law for mandatory reporting of gunshot wounds would do.

Ovens points to US laws for the reporting of gunshot wounds as a model to follow, and yet Canada and the United States have different cultures, and the level of gun violence is dramatically higher in the United States. US laws for reporting gunshot wounds have many critics as well. ${ }^{3}$

Firearm education and gun safety efforts should be enhanced. Psychiatric services must be made easily accessible to suicidal patients. Databases of firearm-related violence should be created. All of these goals can be accomplished without new legislation and without requiring physicians to report gunshot wounds to the police. A law for the mandatory reporting of gunshot wounds will have few benefits, interfere with the care of patients and place physicians in an inappropriate role.

Merril Pauls is with the Departments of Emergency Medicine and Bioethics and Jocelyn Downie is with the Health Law Institute and the Faculties of Law and Medicine, Dalhousie University, Halifax, NS.

Competing interests: None declared.

\section{References}

1. Mackay B. Gunshot wounds: the new public health issue. CMA7 2004;170(5):780.

2. Canadian Medical Association. Firearms control (update 2001) [policy statement]. Ottawa: The Association; 2001. Available: www.cma.ca/staticContent /HTML/N0/12/where_we_stand/firearms.pdf (accessed 2004 Mar 18).

3. Hargarten SW, Waeckerle JF. Docs and cops: A collaborating or colliding partnership? Ann Emerg Med 2001;38(4):438-40.

Correspondence to: Merril Pauls, Department of Bioethics, 5849 University Ave., Dalhousie University, Halifax NS B3H 4H7; fax 902 494-3865; merril.pauls@dal.ca 